\title{
A Novel Plant Ferredoxin-Like Protein and the Regulator Hor Are Quorum-Sensing Targets in the Plant Pathogen Erwinia carotovora
}

\author{
Solveig Sjöblom, Heidi Harjunpää, Günter Brader, and E. Tapio Palva \\ Viikki Biocenter, Faculty of Biosciences, Department of Biological and Environmental Sciences, Division of Genetics, \\ University of Helsinki, P.O.Box 56, FIN-00014, Helsinki, Finland
}

Submitted 15 November 2007. Accepted 12 March 2008.

\begin{abstract}
Quorum sensing (QS), a population-density-sensing mechanism, controls the production of the main virulence determinants, the plant cell-wall-degrading enzymes (PCWDEs) of the soft-rot phytopathogen Erwinia carotovora subsp. $\mathrm{ca}$ rotovora. In this study, we used random transposon mutagenesis with a gusA reporter construct to identify two new QS-controlled genes encoding the regulator Hor and a plant ferredoxin-like protein, FerE. The QS control of the identified genes was executed by the QS regulators ExpR1 and ExpR2 and mediated by the global repressor RsmA. Hor was shown to contribute to bacterial virulence at least partly through its control of PCWDE production. Our results showed that FerE contributes to oxidative stress tolerance and in planta fitness of the bacteria and suggest that QS could be central to control of oxidative stress tolerance. The presence of the FerE protein appears to be rather unique in heterotrophic bacteria and suggests an acquisition of the corresponding gene from plant host by horizontal gene transfer.
\end{abstract}

Additional keywords: acylhomoserine lactone, AHSL, ExpI, Pectobacterium carotovorum.

Bacteria use a cell-to-cell communication system, referred to as quorum sensing (QS), to monitor their population density and to regulate a wide variety of functions accordingly (Fuqua et al. 2001; Waters and Bassler 2005). These include bioluminescence in Vibrio fischerii (Eberhard et al. 1981; Engebrecht and Silverman 1984), conjugal plasmid transfer in Agrobacterium tumefaciens (Zhang et al. 1993), biofilm formation and virulence in Pseudomonas aeruginosa (Parsek and Greenberg 2000; Winson et al. 1995), production of the exopolysaccharide stewartan in Pantoea stewartii (Beck von Bodman and Farrand, 1995), and carbapenem antibiotics and plant cellwall-degrading enzymes (PCWDEs) in Erwinia carotovora subsp. carotovora (also referred to as Pectobacterium carotovorum) (Bainton et al. 1992; Jones et al. 1993; Pirhonen et al. 1993).

In contrast to the divergence of QS-controlled processes, the basic QS system is similar in many gram-negative bacteria. QS is achieved by the production and sensing of diffusible signal

Corresponding author: Tapio Palva; Telephone: +358-9-19159600; Fax: +358-9-19159076; E-mail:tapio.palva@helsinki.fi

* The $e$-Xtra logo stands for "electronic extra" and indicates a supplemental figure is published online. molecules, $N$-acylhomoserine lactones (AHSL), synthesized by an AHSL synthase, an enzyme of the LuxI family and recognized by a QS regulator, a transcription factor of the LuxR family that in turn controls the expression of downstream genes (Fuqua et al. 2001; Whitehead et al. 2001). Different bacteria produce AHSL with diverse acyl side chain lengths (4 to 16 carbons and with alterations in the oxidative status) that are recognized by a QS regulator specific for the cognate AHSL. Depending on the strain, E. carotovora subsp. carotovora produces mainly either 3-oxo-hexanoylhomoserine lactone (3-oxo-C6-HSL) or 3-oxo-octanoylhomoserine lactone (3-oxoC8-HSL) as the major AHSL, with 3-oxo-C8-HSL as the cognate AHSL of E. carotovora subsp. carotovora SCC3193 (Brader et al. 2005). Normally, the QS regulator is unable to respond to noncognate AHSL. This confers a high degree of specificity to the QS system and suggests that QS is mainly involved in intraspecies communication (Fuqua and Greenberg 2002; Lazdunski et al. 2004; Pappas et al. 2004). The QS regulators are structurally similar, with a ligand (AHSL)-recognizing domain and a conserved DNA-binding domain. Although proteins of the LuxR family have similar structures, their operative mechanisms vary, with some acting as activators and others as repressors. Additionally, some QS regulators bind to DNA in an AHSL-bound form (Pappas et al. 2004; Qin et al. 2000; Whitehead et al. 2002), whereas others bind to DNA and activate transcription in an AHSL-free form, as shown for the EsaR of Pantoea stewartii (Minogue et al. 2002, 2005) and the ExpR proteins of E. carotovora subsp. carotovora (Cui et al. 2006; Sjöblom et al. 2006).

The QS regulators of E. carotovora subsp. carotovora

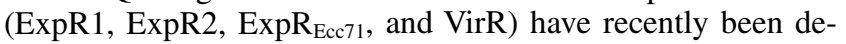
scribed more extensively. Many E. carotovora subsp. carotovora strains characterized appear to possess two ExpR proteins (Burr et al. 2006; Cui et al. 2006; Sjöblom et al. 2006). Interestingly, we could show that the two ExpR proteins of SCC3193 have different ligand-binding specificities, with the ExpR1 protein recognizing only the cognate AHSL (3-oxo-C8HSL) whereas the ExpR2 protein recognized both cognate and noncognate (e.g., 3-oxo-C6-HSL) AHSL (Sjöblom et al. 2006). In the absence of AHSL, the two ExpR proteins function as negative virulence regulators, as indicated by restoration of virulence to the avirulent expI mutant by inactivating both expR1 and expR2 (Sjöblom et al. 2006). However, the negative control of virulence by the ExpR proteins is not direct but mediated through the global negative regulator RsmA, an RNAbinding protein (Chatterjee et al. 1995, 2005; Cui et al. 2006; Sjöblom et al. 2006). In the AHSL free state, the ExpR1 and ExpR2 proteins bind to the $\operatorname{rsm} A$ promoter, activating its tran- 
scription and leading to a suppressed virulence. On the other hand, accumulation of the cognate AHSL releases binding of both ExpR proteins and the $r s m A$ expression is downregulated, allowing expression of downstream genes such as those for PCWDEs, enhancing virulence (Cui et al. 2006; Sjöblom et al. 2006). The addition of the noncognate AHSL releases only the ExpR2 protein, showing that ExpR1 alone is sufficient to activate $\operatorname{rsm} A$ transcription and downregulate the downstream genes (Cui et al. 2006; Sjöblom et al. 2006).

Recent transcriptome and proteome analysis have expanded our knowledge of the QS regulons of different gram-negative bacteria (Chen et al. 2003; Qin et al. 2007; Schuster et al. 2003; Wagner et al. 2003). These studies reveal that, in many cases, QS is a global regulatory system affecting a diverse set of both physiological and metabolic processes (e.g., in $\mathrm{Pseu}$ domonas aeruginosa, over 400 genes are controlled by QS). QS also regulates or fine tunes other regulatory circuits, such as the Rap regulator in Serratia. Rap (a homolog of Hor in Erwinia spp.) controls the production of the secondary metabolite prodigiosin (Thomson et al. 1997).

In E. carotovora subsp. carotovora that causes soft rot in a variety of economically important crops worldwide (Perombelon 2002), QS is a central regulator of the main softrot-causing determinants, the PCWDEs, including cellulases,

A

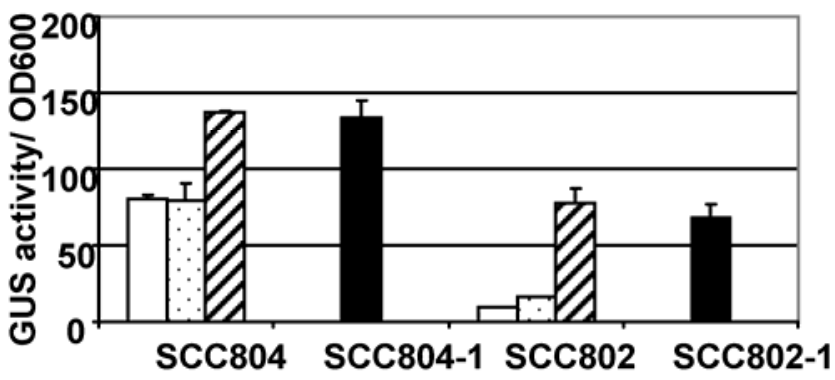

$\mathrm{B}$

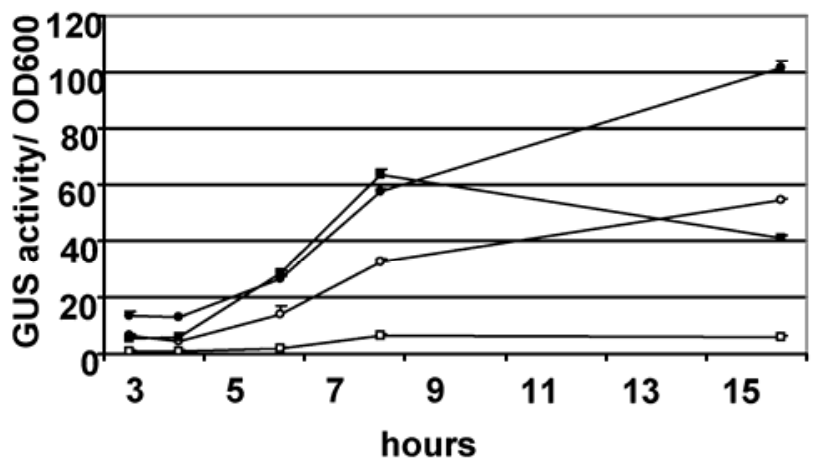

Fig. 1. A, Cognate $N$-acylhomoserine lactone (AHSL), 3-oxo-octanoylhomoserine lactone (3-oxo-C8-HSL), is needed for full expression of the newly identified quorum-sensing (QS) target genes. $\beta$-Glucuronidase (GUS) activity was determined for Erwinia carotovora subsp. carotovora strains SCC804 and SCC802 grown to an optical density at $600 \mathrm{~nm}$ $\left(\mathrm{OD}_{600}\right)$ of approximately 2.8 , in L medium without AHSL (open bars), with $1 \mu \mathrm{M} 3$-oxo-hexanoylhomoserine lactone (dotted bars), or with $1 \mu \mathrm{M}$ 3-oxo-C8-HSL (striped bars) added. In addition, GUS activity was determined for E. carotovora subsp. carotovora strains SCC804-1 and SCC802-1 (black bars) (corresponding single mutants with the transposon insertion transferred to wild-type background) grown in $\mathrm{L}$ medium to $\mathrm{OD}_{600}$ of approximately 2.8. B, QS dependence of the target gene expression was assessed by analyzing the GUS activity of the mutants SCC802 (open squares), SCC802-1 (closed squares), SCC804 (open circles), and SCC804-1 (closed circles) at different growth phases. Bars represent standard deviations. polygalacturonases, pectinases, and proteinases (Barnard and Salmond 2007; Jones et al. 1993; Pirhonen et al. 1991, 1993). E. carotovora subsp. carotovora mutants deficient in the AHSL synthesizing enzyme ExpI are impaired in the production of PCWDEs and, consequently, are avirulent (Jones et al. 1993; Pirhonen et al. 1993). Furthermore, in some strains of $E$. carotovora subsp. carotovora, QS has been shown to control also the production of carbapenem antibiotics (Bainton et al. 1992; McGowan et al. 1995) and to regulate the virulence factors Svx, a secreted homologue of AvrXca of Xanthomonas campestris (Corbett et al. 2005), and Nip, an elicitor of plant necrosis (Pemberton et al. 2005).

The aim of this study was to further explore the QS regulon in E. carotovora subsp. carotovora. Using a transposon mutant screen, we identified two new QS-controlled genes in E. carotovora subsp. carotovora: a gene encoding a putative plant ferredoxin-like protein and another encoding the regulator Hor. We show that both of these target genes are negatively regulated by ExpR1 and ExpR2 in the absence of AHSL. This regulation appears to be largely mediated through the global negative regulator RsmA. Interestingly, we could show that QS controls oxidative stress tolerance in E. carotovora subsp. carotovora and that the QS-controlled plant ferredoxin-like protein contributes to this tolerance. The presence of the plant ferredoxin-like gene in E. carotovora subsp. carotovora points to a potential horizontal gene transfer from a eukaryotic host.

\section{RESULTS}

A plant ferredoxin-like protein and the regulator Hor identified as QS targets in a transposon mutagenesis screen.

Previously, we have shown that, in E. carotovora subsp. carotovora SCC3193, the main virulence determinants, PCWDEs, are controlled by QS (Pirhonen et al. 1993). Further, we have demonstrated that this control is mediated by the global negative regulator RsmA, a target of the QS regulators ExpR1 and ExpR2 in E. carotovora subsp. carotovora SCC3193 (Sjöblom et al. 2006). To identify new QS-regulated genes, we employed random transposon mutagenesis by introducing the mini-Tn5Cm ${ }^{\mathrm{r}}::$ gusA transposon into the AHSL negative $\operatorname{expI}$ mutant (SCC3065, expI:: $\mathrm{Km}^{\mathrm{r}}$ ) (Pirhonen et al. 1993). To identify genes responsive to AHSL, approximately $10,000 \mathrm{Km}^{\mathrm{r}} \mathrm{Cm}^{\mathrm{r}}$ transposon mutants were screened for $\beta$-glucuronidase (GUS) activity with or without $1 \mu \mathrm{M} 3$-oxo-C6HSLs. From 70 putative mutants picked for further testing, seven were analyzed by quantitative GUS assays. The quantitative GUS assay revealed that two of the mutant strains, SCC802 and SCC804, were clearly responsive to the cognate 3-oxo-C8-HSL of SCC3193 (Fig. 1A). For further studies and to elucidate the expression level of the newly identified QS candidate targets, the mutations were transduced to wild-type SCC3193 background. The AHSL-induced GUS activity of the single mutants SCC802-1 and SCC804-1 was shown to be similar to that of SCC802 and SCC804 double mutants (Fig. 1A). To explore the QS dependence of the mutants and requirement for endogenous AHSL production, GUS activity was assayed (Fig. 1B). These results show that, in the mutant SCC802, the GUS activity is strongly dependent on the presence of expI. Similarly, in the SCC804 mutant, the GUS activity responds to the AHSL production, although the basal GUS activity of the SCC804 mutant is higher than that of the SCC802 strain.

To identify the new AHSL-responsive genes tagged by the mini-Tn5Cm::gusA, the regions flanking the insertion were cloned by arbitrary polymerase chain reaction (PCR) (CaetanoAnnoles 1993; O'Toole and Kolter 1998) and sequenced. In the SCC804 mutant, the transposon was inserted into a 438-bp 
the ExpR1 and ExpR2 have different AHSL specificities (Sjöblom et al. 2006). To elucidate whether the ExpR proteins act in the same manner in this context, the wild-type SCC3193 and the mutant strains expI (SCC3065), expI expRI (SCC6005), expI expR2 (SCC908), and expI expR1 expR2 (SCC906) were grown without the addition of any AHSL or in the presence of either 3-oxo-C8-HSL or 3-oxo-C6-HSL, and the accumulation of ferE and hor mRNAs was characterized by Northern blot analysis (Fig. 4). Our results show that, in the expI mutant lacking the AHSL synthase, the expression of both target genes is downregulated whereas, after addition of the cognate AHSL 3-oxo-C8-HSL, both the ferE and hor genes are fully expressed. This is in accordance to the results obtained with the GUS assay (Fig. 1). In addition, the Northern blot

A
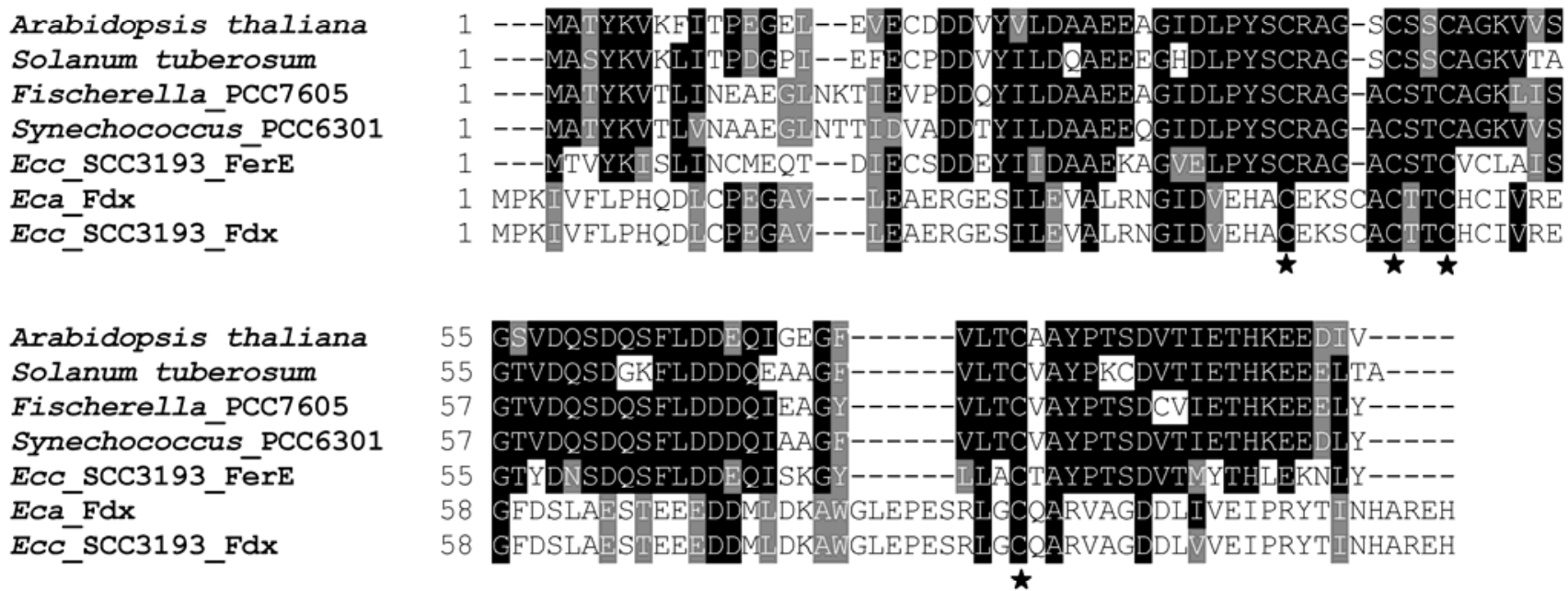

B

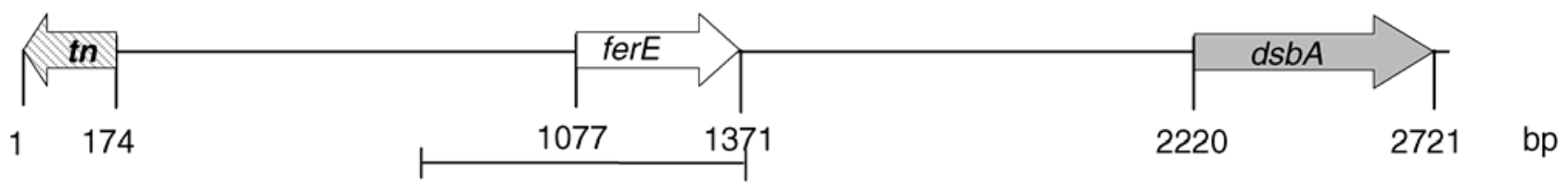

Fig. 3. A, Deduced amino acid sequence of FerE of Erwinia carotovora subsp. carotovora SCC 3193 and its alignment with other ferredoxin amino acid sequences. The sequences are from E. carotovora subsp. carotovora SCC3193 (FerE_EU274296), Arabidopsis thaliana (FedA_NP_176291), Solanum tuberosum (Fed1_CAC38395), E. carotovora subsp. atroseptica SCRI1043 (Fdx_YP_051321), E. carotovora subsp. carotovora SCC3193 (Fdx), Fischerella sp. strain PCC7605 (PetF_AAC04840), and Synechococcus sp. strain PCC6301 (PetF_BAD80674). The four conserved cysteine residues have been indicated with asterisks. B, The ferE locus of E. carotovora subsp. carotovora SCC3193. The ferE gene is shown (in white) together with the flanking genes: $d s b A$ (40\% identity to DsbA oxidoreductase from Azotobacter vinelandii) and tn (77\% identity to a putative transposase YPCD1.93 in Yersinia pestis CO92). The alignments were performed using the CLUSTALW program (Thompson et al. 1994) and shaded using the BOX shade program (version 3.21; EMBnet website). The arrows show the direction of the reading frames and the striped arrow indicate that we only have a partial sequence. The complementing fragment is indicated as a line.

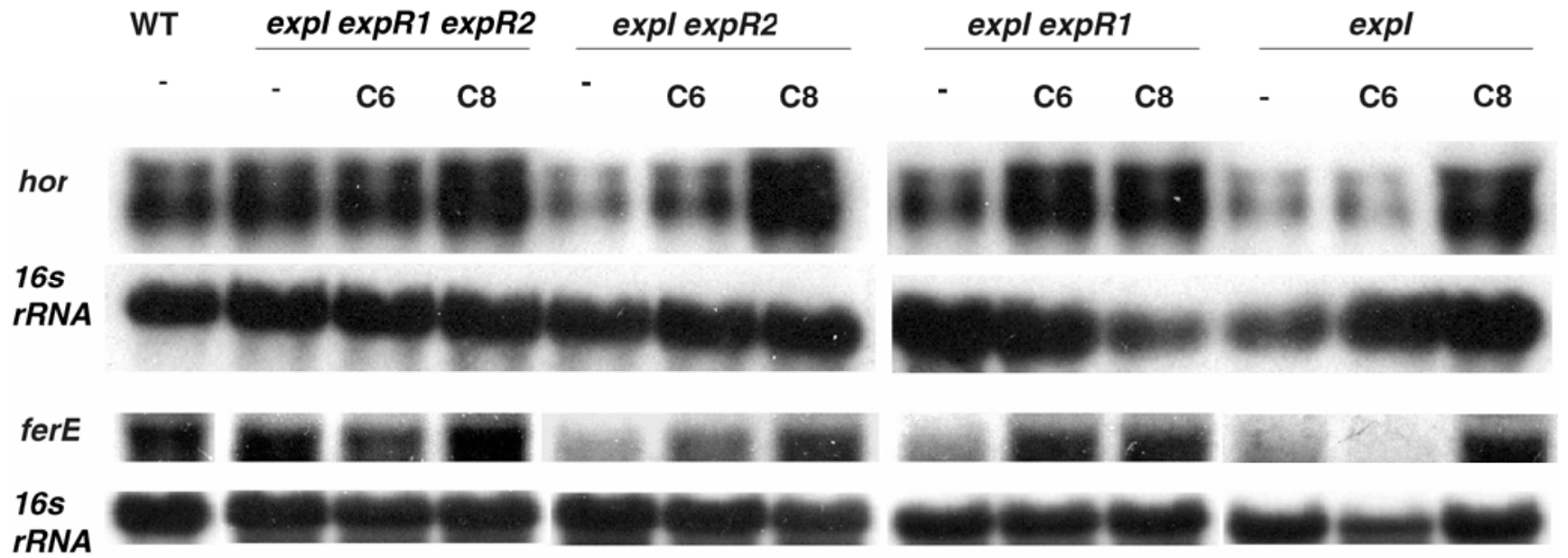

Fig. 4. ExpR1- and ExpR2-dependent regulation of ferE and hor. Northern blot analysis of total RNA from Erwinia carotovora subsp. carotovora wild-type

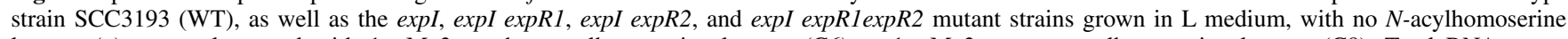
lactone (-) or supplemented with $1 \mu \mathrm{M}$ 3-oxo-hexanoylhomoserine lactone (C6) or $1 \mu \mathrm{M}$ 3-oxo-octanoylhomoserine lactone (C8). Total RNAs were extracted from cells at logarithmic phase of growth (optical density at $600 \mathrm{~nm}=1.2$ ). RNA was hybridized with ferE, hor, and $16 \mathrm{~S}$ rRNA probes. 
analysis reveals that both ExpR1 and ExpR2 have specific roles in the control of ferE and hor genes. In the $\operatorname{expI} \operatorname{expRI}$ mutant, the expression of ferE and hor is activated with the addition of either 3-oxo-C8-HSL or 3-oxo-C6-HSL whereas, in the expI expR2 mutant, the target gene expression is only activated by physiological concentrations of the cognate 3oxo-C8-HSL. In the expI expR1 expR2 triple mutant, both ferE and hor are unregulated, even without any AHSL addition. This suggests that, in the absence of AHSL, ExpR1 and ExpR2 act as negative regulators of $f e r E$ and hor and that this negative regulation is released by the addition of AHSL. In accordance with our previous studies of AHSL regulation of PCWDEs (Sjöblom et al. 2006), we have shown here that the QS regulators ExpR1 and ExpR2 control expression of hor and ferE in an AHSL specificity-dependent manner. Taken together, the results demonstrate identification of two novel QS (AHSL)regulated genes, ferE and hor, in the E. carotovora subsp. carotovora SCC3193.

\section{Regulation of hor and ferE is mediated via the global negative regulator $\operatorname{RsmA}$.}

Our results (Fig. 4) demonstrated that, in the absence of AHSL, ExpR1 and ExpR2 are negative regulators of ferE and hor. However, our results do not show whether this repression is direct or mediated by some other regulator. An involvement of the global negative regulator RsmA in QS of E. carotovora subsp. carotovora was suggested in our previous study, showing that both ExpR1 and ExpR2 activate transcription of $r s m A$ in the absence of AHSL and that expression of $r s m A$ was fully prevented by addition of the cognate 3-oxo-C8-HSL (Sjöblom et al. 2006). We explored the role of RsmA in controlling ferE and hor expression by Northern blot analysis (Fig. 5A) using an expI mutant and an expI rsmA double mutant strain. This analysis revealed that, in the $\operatorname{expI} r \operatorname{smA}$ double mutant, the presence of AHSL is not required for the expression of hor and ferE, in contrast to the expI mutant, where presence of the cognate AHSL is necessary. To further support the role of RsmA as the negative regulator of ferE and hor, we analyzed the expression of these genes in an expI rsmA double mutant in the presence and absence of the $\operatorname{expI^{+}}$ allele, mimicking the phenotype of an $r s m A$ single mutant. This presence of the expI ${ }^{+}$ allele did not alter the ferE or hor expression observed in the expI rsmA double mutant, supporting a repressive role of $r s m A$ (Fig. 5B). Taken together, our results suggest that both ferE and hor are controlled by RsmA, which in turn is controlled by the QS regulators ExpR1 and ExpR2 in an AHSL-dependent manner.

\section{Hor contributes to virulence of E. carotovora subsp. carotovora.}

Previous studies have demonstrated that the QS system controls the production of PCWDEs and, thus, is one of the most important factors regulating virulence in E. carotovora subsp. carotovora. To elucidate the possible role of the above-identified new QS-controlled genes in virulence, we first characterized the capacity of the corresponding mutants to macerate potato tubers. Potato tuber slices (cv. Van Gogh) were inoculated with the wild-type strain SCC3193 and the expI, hor, ferE, expI hor, or expI ferE mutants (Fig. 6B). To ensure that the differences in maceration capacity were due to defects in virulence determinants rather than in the growth properties of the different strains, the growth of the strains was determined in both complete and minimal media (Supplementary Figure S1). These results indicate that the observed differences in maceration cannot be explained by differences in bacterial growth. As expected, the avirulent expI mutant showed almost no maceration. Similarly, the expI ferE and expI hor double mutants were not able to macerate potato tubers. The hor single mutant showed substantially reduced capacity of maceration, while the ferE mutant was similar to the wild type. The impaired maceration capacity of the hor mutant is in accordance with its reduced production of PCWDEs as assessed by enzyme indicator plates (Fig. 6A). In addition, we showed that the reduced PCWDE production of the hor mutant could be complemented by expressing the hor gene in trans. To further assess the virulence of the hor and ferE mutants, leaves of A. thaliana Col-0 plants were inoculated with the wild-type strain SCC3193, the expI mutant, the hor mutant, or the ferE mutant. These results were similar to those of the potato maceration assay, with the expI mutant showing almost no maceration, the hor mutant showing clearly reduced maceration, and the ferE mutant and the wild-type showing similar level of maceration of leaf tissue (Fig. 6C). Taken together, the results clearly suggest that the Hor regulator contributes to the virulence and development of disease symptoms by the E. carotovora subsp. carotovora SCC3193.

To investigate the possible role of Hor and FerE in the infection process, we measured the in planta growth of the respective mutants in A. thaliana Col-0. This analysis revealed that both the hor and the ferE single mutants showed slightly reduced growth compared with the wild-type SCC3193, although the reduction was not as clear as with the avirulent $\operatorname{expI}$ mutant (Fig. 6D). This suggests that both Hor and FerE contribute to the overall fitness of the bacteria during infection.

QS regulates oxidative stress tolerance in the plant pathogen $E$. carotovora subsp. carotovora.

The ferE gene of E. carotovora subsp. carotovora encodes a plant ferredoxin-like protein present in plants and photo-

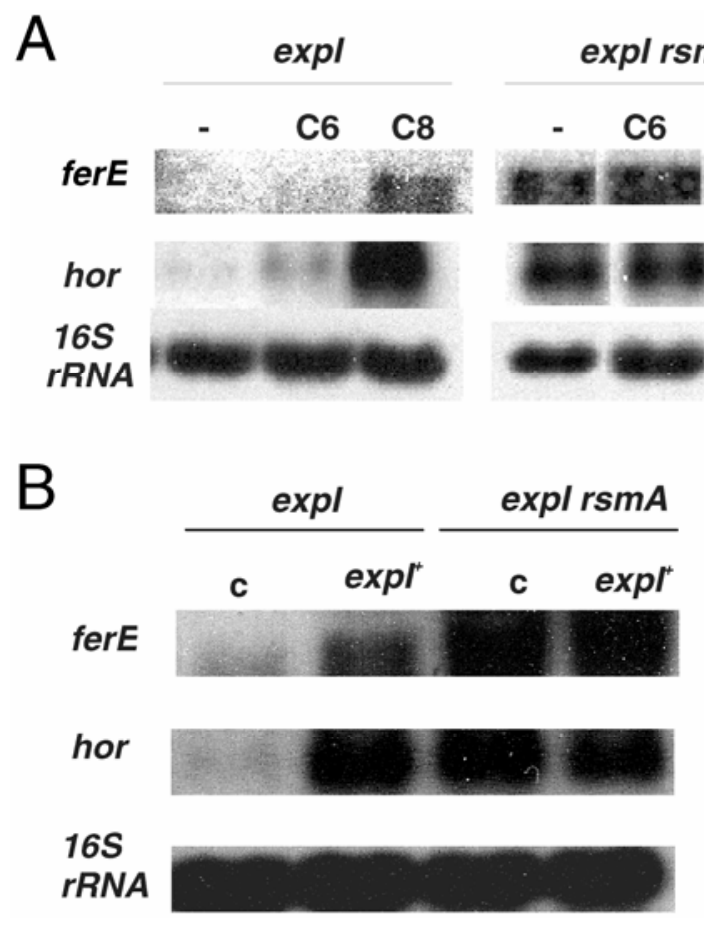

Fig. 5. Quorum-sensing control of ferE and hor is mediated by RsmA. A, Northern blot analysis of total RNA from expI and expI rsmA mutant strains grown in L medium with no $\mathrm{N}$-acylhomoserine lactone (-) or supplemented with either $1 \mu \mathrm{M}$ 3-oxo-hexanoylhomoserine lactone (C6) or 1 $\mu \mathrm{M}$ 3-oxo-octanoylhomoserine lactone (C8). B, Northern blot analysis of total RNA from expI and expI rsmA mutants strains with $\exp _{\mathrm{ISCC} 3193}$ expressed in trans; "c" indicates vector control pBluescript SK+. Total RNAs were extracted at logarithmic phase of growth (optical density at $600 \mathrm{~nm}=$ 1.2). RNA was hybridized with ferE, hor, and $16 \mathrm{~S}$ rRNA probes. 
synthetic cyanobacteria (Fig. 3A). The ferE gene of E. carotovora subsp. carotovora SCC3913 appears to be a novel acquisition in heterotrophic bacteria sequenced up to today. The FerE protein is most similar to ferredoxins PetF (BAD80674) of Synechococcus elongatus PCC 6301 (62\% identity and $79 \%$ similarity) and PetF (AAC04840) of Fischerella subsp. PCC7605 (64\% identity and 76\% similarity); to plant ferredoxins, including FedA (NP_176291) of $A$. thaliana $(56 \%$ identity and $76 \%$ similarity) and FedI (CAC38395) of Solanum tuberosum (58\% identity and 73\% similarity) (Fig. 3A); and to putative plant ferredoxins from I. aggregata $(63 \%$ identity and $75 \%$ similarity to DT575297.1) and soybean (61\% identity and $73 \%$ similarity to BU764558.1). FerE of E. carotovora subsp. carotovora showed only very limited similarity to a putative bacterial ferredoxin Fdx (26\% identity and $48 \%$ similarity) in the se-
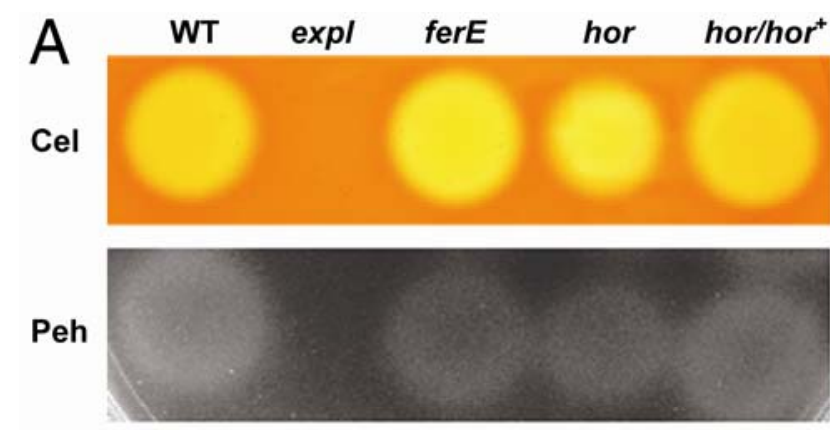

B
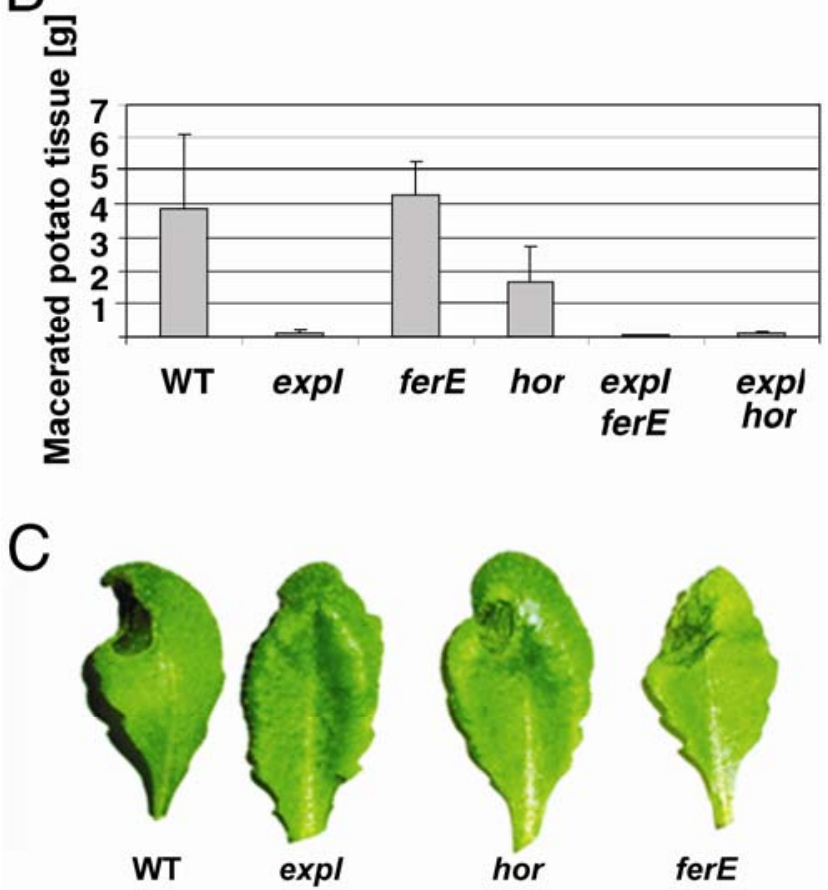

D

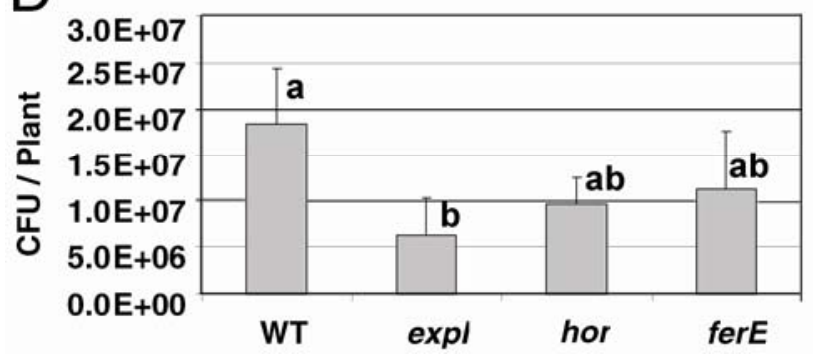

quenced genome of E. carotovora subsp. atroseptica (Fig. 3A). Moreover, a putative Fdx protein was also found in the E. carotovora subsp. carotovora SCC3193 with an amino acid sequence almost identical (99\% identity and 100\% similarity) to the E. carotovora subsp. atroseptica Fdx sequence (unpublished). The presence of the plant-type ferredoxin found here suggests that it may have a separate role from the $\mathrm{Fdx}$ of E. carotovora subsp. atroseptica and E. carotovora subsp. carotovora.

The FerE of SCC3193 contains a conserved iron-sulfurbinding domain $2 \mathrm{Fe}-2 \mathrm{~S}$, which plays an important role in electron transfer processes and in various enzymatic reactions (Marchler-Bauer et al. 2007). In Escherichia coli and Erwinia chrysanthemi, proteins with iron-sulfur clusters have been shown to have an effect on the bacterial tolerance to oxidative stress (Koo et al. 2003; Ollagnier-de Choudens et al. 2003). To explore whether the FerE of SCC3193 is involved in oxidative stress tolerance, we assessed the susceptibility of the wild-type strain SCC3193, the expI mutant, and the ferE mutant to $\mathrm{H}_{2} \mathrm{O}_{2}$. These strains were exposed to 20, 30 , and $40 \mathrm{mM} \mathrm{H}_{2} \mathrm{O}_{2}$ and their survival rate was compared with that of the wild-type strain SCC3193 (Fig. 7A). Our results demonstrate a clear concentration-dependent reduction in oxidative stress tolerance in the ferE mutant strain. This is in contrast to the hor mutant that exhibited wild-type levels of oxidative stress tolerance (data not shown). These results show for the first time that, in the plant-pathogenic E. carotovora subsp. carotovora, the oxidative stress tolerance is partly mediated via FerE. Further, our data show that the AHSL-deficient expI mutant is even more sensitive to oxidative stress, with $40 \mathrm{mM} \mathrm{H} \mathrm{O}_{2}$ concentration being lethal for this mutant. This deficiency in oxidative stress tolerance in the expI mutant could be complemented with the addition of $1 \mu \mathrm{M}$ 3-oxo-C8-HSL (Fig. 7B). To confirm the contribution of FerE to the oxidative stress tolerance, we expressed ferE in trans in both the ferE mutant and the expI mutant (Fig. 7C). This experiment demonstrated that the reduced oxidative stress tolerance of the ferE mutant was complemented by the addition of the $\mathrm{ferE}^{+}$in trans. Introduction of the $\mathrm{ferE}^{+}$ clone to the expI mutant partially restored the oxidative stress tolerance of the $\operatorname{expI}$ mutant. Taken together, our results suggest that, in the plant pathogen E. carotovora subsp. carotovora, QS controls oxidative stress tolerance and that the cognate 3-oxo-C8-HSL is required for this tolerance. Moreover, it shows that FerE contributes to this QS-controlled oxidative stress tolerance.

Fig. 6. Role of hor and ferE in virulence. A, Exoenzyme indicator plates showing the production of cellulases (Cel) and pectinases (Peh) from 10- $\mu \mathrm{l}$ culture supernatant of the following strains: wild-type SCC3193 (WT), expI mutant, ferE mutant, hor mutant, and hor mutant with hor expressed in trans. B, Potato tuber slices were inoculated with the following Erwinia carotovora subsp. carotovora strains: WT SCC3193, expI mutant, ferE mutant, hor mutant, expI ferE double mutant, and expI hor double mutant using a bacterial inoculum of $10^{5} \mathrm{CFU}$. At $72 \mathrm{~h}$ after inoculation, the macerated tissue of the potato was weighed to determine the maceration capacity. $\mathbf{C}$, Leaves of Arabidopsis thaliana accession Col-0 were locally inoculated with the same strains as in A using an inoculum of $10^{4} \mathrm{CFU}$ and the symptoms were documented after $48 \mathrm{~h}$. Representative leaves of the experiment are shown. D, To determine the bacterial growth in planta of the above $E$. carotovora subsp. carotovora strains in A. thaliana Col-0, plant samples were taken at $48 \mathrm{~h}$ post inoculation and the amount of living bacteria was determined according to Materials and Methods. The result shows an average of six infected plants. Different letters at data points indicate significant differences $(P<0.05)$ calculated with data of all replicates at each time point with one-way analysis of variance and Tukey's honestly significantly different test. Bars represent standard deviations. 


\section{DISCUSSION}

QS is central to virulence regulation in the soft-rot plant pathogen E. carotovora subsp. carotovora. In previous studies, we have shown that the production of PCWDEs, which are the main virulence determinants and required for plant tissue maceration, is repressed in the expI mutant lacking the AHSL synthase (Pirhonen et al. 1991, 1993). Recent data demonstrate that two QS regulators, ExpR1 and ExpR2, with distinct AHSL specificities are key sensors of AHSL in E. carotovora subsp.

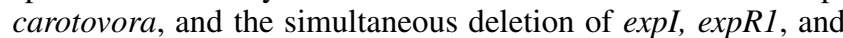
$\operatorname{expR2}$ genes leads to a constitutive activation of PCWDE production (Sjöblom et al. 2006).

To explore whether QS could control the expression of additional virulence-related genes in E. carotovora subsp. carotovora, we employed a random transposon mutagenesis with a mini-Tn5 $\mathrm{Cm}^{\mathrm{r}}:$ :gusA transposon in $\operatorname{expI}$ background. A screen for AHSL-responsive genes identified two new QS-regulated genes which have not been identified in earlier QS screening studies performed in E. carotovora subspecies (Corbett et al. 2005; Pemberton et al. 2005). In this study, we present three major findings. First, we demonstrate the identification of two new QS-regulated genes, encoding the regulator Hor and a putative novel plant ferredoxin-like protein, FerE. FerE is similar to cyanobacteria and plant ferredoxins but with very limited similarity to bacterial ferredoxins sequenced up to today. Second, we provide data showing that these newly identified genes are regulated by the QS regulators ExpR1 and ExpR2 and the regulation is, to a large extent, mediated by the negative regulator RsmA. Third, we show that QS controls oxidative stress tolerance in E. carotovora subsp. carotovora and that FerE is part of this regulon contributing to QS-dependent oxidative stress tolerance.

Northern blot analysis was used to demonstrate how QS regulation of hor and the ferE is executed. As we have shown previously for PCWDE production (Sjöblom et al. 2006), the QS regulators ExpR1 and ExpR2 seem to repress hor and ferE expression in the absence of AHSL. This repression is abolished by addition of the cognate 3-oxo-C8-HSL leading to expression of hor and ferE. In our previous study, we also showed a difference in AHSL recognition specificity between the ExpR1 and ExpR2 proteins, with ExpR1 acting as a cognate ligand-specific regulator and ExpR2 acting as a more promiscuous regulator, responding to both cognate and noncognate signals (Sjöblom et al. 2006). Our results demonstrate that ExpR1 and ExpR2 act in a similar way, controlling hor and ferE expression. In the expI expRI double mutant, transcription of hor and ferE was induced by both 3-oxo-C6-HSL and 3-oxo-C8-HSL whereas, in the expI expR2 double mutant, the hor and fer were induced only by the cognate 3-oxo-C8-HSL (Fig. 8).

However, these data do not demonstrate whether ExpR1 and ExpR2 directly control the newly identified QS target genes or whether the regulation is mediated by some other factor. We and others have recently demonstrated that the ExpR control of PCWDEs is mediated by RsmA (Cui et al. 2006; Sjöblom et al. 2006), an RNA-binding protein that negatively regulates PCWDE gene expression (Chatterjee et al. 2005). Northern blot analysis showed that hor and ferE expression is indeed controlled in a similar fashion. Our results suggest that, in addition to PCWDE genes, hor and ferE could be targets of the global negative regulator RsmA in E. carotovora subsp. carotovora (Fig. 8). Additional RsmA targets in E. carotovora subsp. carotovora (strain Ecc71) have earlier been shown to include also $\mathrm{HrpN}_{\mathrm{Ecc}}$ (Cui et al. 1996). In P. aeruginosa, RsmA is known to regulate several virulence-related genes, including the rhamnolipid biosynthetic operons, hydrogen cyanide, and
AHSL synthase genes (Heurlier et al. 2004; Pessi et al. 2001). Additionally, a recent transcriptome analysis performed in $P$. aeruginosa with an $r s m A$ mutant revealed several potential RsmA target genes (Burrowes et al. 2006). It remains to be elucidated whether all QS regulation in E. carotovora subsp. carotovora SCC3193 is executed by RsmA or whether there is also an RsmA-independent QS pathway. Furthermore, it remains to be solved whether there are other targets besides $r s m A$ regulated directly by either ExpR 1 or ExpR2 in E. carotovora subsp. carotovora.

The two genes of the QS regulon identified in this study represent two different kinds of proteins, a transcriptional regula-
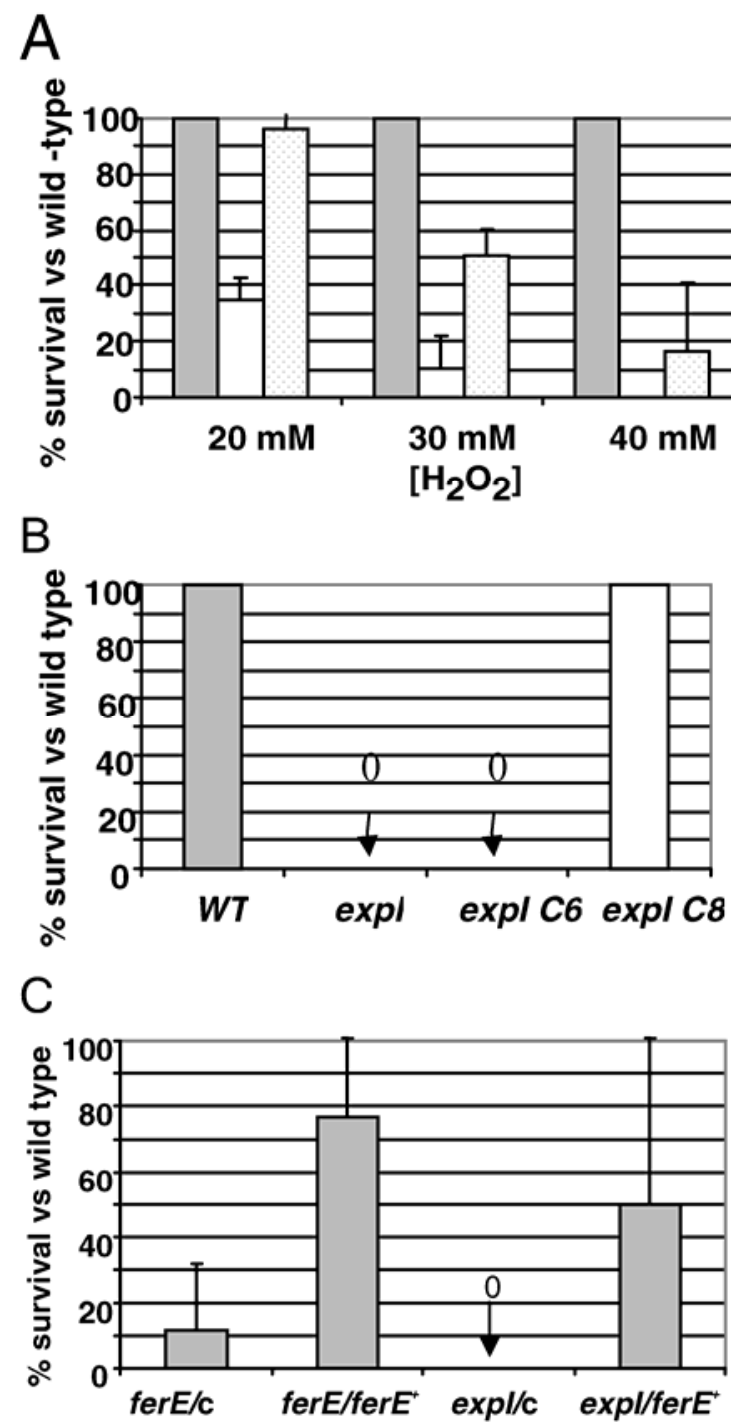

Fig. 7. Role of ferE and expI in oxidative stress tolerance of Erwinia carotovora subsp. carotovora. A, The wild-type SCC3193 (WT) (gray bars), expI mutant (white bars), and ferE mutant (dotted bars) strains of E. carotovora subsp. carotovora were exposed to 20,30 , and $40 \mathrm{mM} \mathrm{H}_{2} \mathrm{O}_{2}$. The number of living bacteria was measured before the addition of $\mathrm{H}_{2} \mathrm{O}_{2}$ and after incubating the cells for $4 \mathrm{~h}$ with $\mathrm{H}_{2} \mathrm{O}_{2}$ by viable counts. The survival of the expI mutant and the ferE mutant was given as percentage of the survival of the WT bacteria. B, Complementation of the oxidative stress susceptibility of expI mutant by $N$-acylhomoserine lactone (AHSL) addition. The indicated strains were grown in L medium without AHSL or supplemented with $1 \mu \mathrm{M}$ 3-oxo-hexanoylhomoserine lactone (C6) or $1 \mu \mathrm{M} 3$ oxo-octanoylhomoserine lactone (C8) and subjected to $40 \mathrm{mM} \mathrm{H}_{2} \mathrm{O}_{2}$ for 4 h. C, For complementation studies, ferE was expressed in trans in the ferE and $\operatorname{expI}$ mutant strains. To test the oxidative stress susceptibility, the indicated strains were grown in $\mathrm{L}$ medium and subjected to $40 \mathrm{mM} \mathrm{H}_{2} \mathrm{O}_{2}$ for 4 $\mathrm{h}$; "c" indicates vector control pQE30. Bars represent standard deviations. 
tor and an enzyme, which highlights the complexity of the QS regulon and variety of genes controlled by the QS. The complexity is also supported by other screens accomplished in $E$. carotovora (Corbett et al. 2005; Pemberton et al. 2005) and in $P$. aeruginosa (Schuster et al. 2003), where proteins involved in diverse cellular functions have been identified. It is interesting to find hor as a QS-controlled gene in E. carotovora subsp. carotovora SCC3193, whereas previous studies suggested that the hor gene is not present in SCC3193 (Thomson et al. 1997) and that hor was not under QS regulation in another E. carotovora subsp. carotovora strain (McGowan et al. 2005). Hor is a member of the MarR/SlyA family of regulatory proteins known to control antimicrobial activities (Thomson et al. 1997). In certain strains of E. carotovora subsp. carotovora, Hor controls the expression of biosynthetic genes for the antibiotic carbapenem, which are also regulated by QS via the regulator CarR of the LuxR family (Holden et al. 1998; Thomson et al. 1997, 2000). In these strains, Hor and QS control of the same genes seem to work in parallel. However, E. carotovora subsp. carotovora SCC3193 appears to lack the carbapenem-synthesizing genes (Holden et al. 1998). Our results demonstrate that, in SCC3193, expression of hor is controlled in an AHSLdependent manner in contrast to the E. carotovora subsp. carotovora ATTn10, where Hor regulation is not under QS control (McGowan et al. 2005). Interestingly, in the opportunistic pathogen Serratia subsp. ATCC39006, the Hor homolog Rap also regulates carbapenem biosynthesis and, in this case, in a QS-dependent manner (Fineran et al. 2005; Slater et al. 2003). Nevertheless, it remains to be clarified whether Hor of the $E$. carotovora subsp. carotovora SCC3193 also has a role in controlling antimicrobial processes as demonstrated for other proteins in the MarR/SlyA family.

To explore other possible functions of Hor in SCC3193, we characterized its role in virulence by both potato tuber maceration and by Arabidopsis leaf inoculations. Both assays clearly revealed reduced maceration capacity of the hor mutant compared with the wild-type E. carotovora subsp. carotovora strain. Furthermore, the hor mutant showed reduced bacterial growth in planta. In accordance with the reduced maceration capacity observed, the production of cellulase and polygalacturonase was also somewhat reduced. This is in accordance with previous results showing reduced plant maceration by a hor mutant of E. carotovora subsp. carotovora ATM101 (Thomson et al. 1997). In conclusion, part of QS control of PCWDE genes and, hence, virulence appears to be directed through Hor in SCC3193.

The ferE gene identified represents a novel gene encoding a plant ferredoxin-like protein in a heterotrophic bacterium. The corresponding putative FerE protein is clearly distinct from normal bacterial ferredoxins (i.e., those found in other plant pathogens). Although the E. carotovora subsp. atroseptica genome of strain SCRI1043 possesses at least 10 genes encoding proteins classified as different kinds of ferredoxins (GenBank BX950851), they are clearly distinct from the plant ferredoxin-like protein characterized in this study. The putative FerE protein of SCC3193 has a conserved 2Fe-2S site (MarchlerBauer et al. 2007) and has high similarity to Ferredoxin I (FedI and PetF) of cyanobacteria (Floss et al. 1997) and to plant ferredoxins of the Fd2 (= FedA) type of Arabidopsis (Hanke et al. 2003). These ferredoxins have been implicated to processes such as nitrogen and sulfur assimilation, sulfite reduction, amino acid and fatty acid metabolism, and redox regulation, as well as mediating electron transfer from the photosystem I (PSI) to ferredoxin NADP reductase (Hanke et al. 2003; Mazouni et al. 2003).

It is interesting to find such a QS-regulated gene in the plant pathogen E. carotovora subsp. carotovora, and its similarity to plant ferredoxins might indicate that the ferE gene of $E$. carotovora subsp. carotovora SCC 3193 has been acquired through HGT. It has been estimated that HGT might contribute to 6 to $21 \%$ of the genes of plant-pathogenic bacteria (Garcia-Vallve et al. 2003). Accordingly, analysis of the genome of E. carotovora subsp. atroseptica indicates a substantial percentage of genes acquired by HGT (Toth et al. 2006). Although most HGT-

\section{In the absence of AHSL}

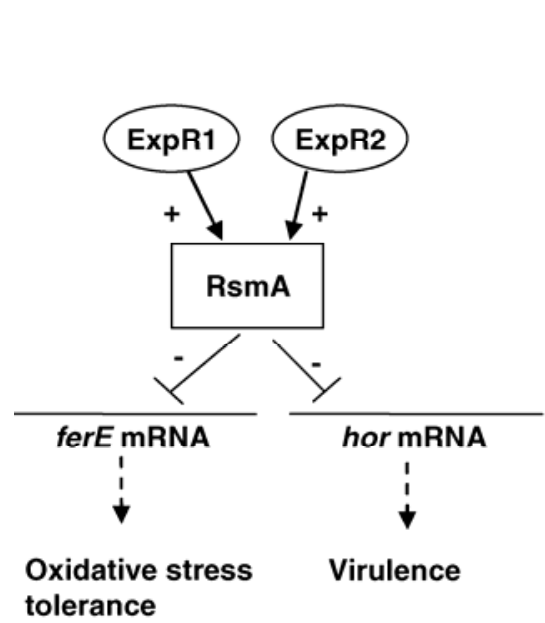

In the presence of 3-oxo-C6-HSL

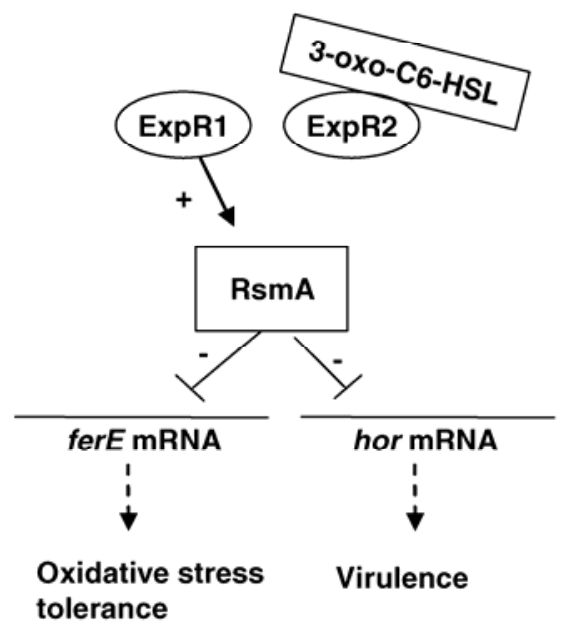

\section{In the presence of 3-0xo-C8-HSL}
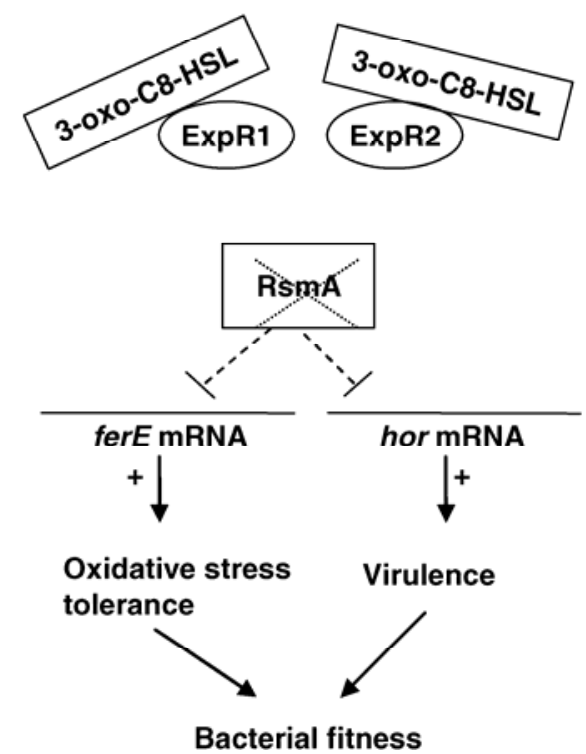

Fig. 8. Schematic model for $N$-acylhomoserine lactone (AHSL)-dependent regulation of oxidative stress tolerance and virulence by ExpR 1 and ExpR2 mediated by RsmA in Erwinia carotovora subsp. carotovora. In the absence of AHSL, both ExpR1 and ExpR2 activate the expression of $r s m A$, negatively regulating oxidative stress tolerance and virulence. After addition of 3-oxo-hexanoylhomoserine lactone (3-oxo-C6-HSL), the ExpR2 is released from the transcriptional activation of $r s m A$, but ExpR1 is still present, activating $r s m A$. In the presence of the cognate 3-oxo-octanoylhomoserine lactone (3-oxo-C8-HSL), both ExpR1 and ExpR2 are released, downregulating $r s m A$. This leads to enhanced expression of ferE and hor, which results in enhanced oxidative stress tolerance and virulence and prompts bacterial fitness in planta. 
derived genes seem to originate from other bacteria, a smaller but still significant number of genes (approximately 1\%), particularly in plant and animal pathogens and symbionts, appear to have been acquired by HGT from eukaryotes (Brown 2003; Koonin et al. 2001). The life style of bacterial pathogens is reflected by genes presumably transferred from animals to the animal pathogen $P$. aeruginosa and by an excess of genes potentially derived from plants to the plant pathogen Xylella fastidiosa (Koonin et al. 2001). Another example of potential HGT from the plant host to E. carotovora subsp. carotovora is provided by the pehA gene encoding a polygalacturonase that shows striking similarity to a corresponding protein in tomato (Hinton et al. 1990; Saarilahti et al. 1990).

HGT from a eukaryotic host seems to be a likely event, because HGT probably is facilitated in the phytosphere and in bacteria with a lifestyle closely associated to plants (van Elsas et al. 2003). However, we cannot rule out the possibility that ferE of E. carotovora subsp. carotovora SCC3193 has been acquired by HGT from cyanobacteria with a similar percentage of identity to FerE as in corresponding plant proteins (64\% identity to Fischerella subsp. PCC7605 ferredoxin PetF; AAC04840).

The putative FerE protein did not appear to be involved in PCWDE production or in the plant tissue maceration in either of the plant assays (Fig. 6B and C). Interestingly, however, the growth rate of ferE mutants in Arabidopsis was slightly compromised. This suggests that ferE could have a role in survival of E. carotovora subsp. carotovora in planta during infection. The presence in FerE of a conserved iron-sulfur binding cluster, often found in enzymes involved in oxidative stress responses (Outten 2007), prompted us to assess the possible role of FerE of SCC3193 in oxidative stress tolerance. Our results demonstrate a substantially reduced tolerance to $\mathrm{H}_{2} \mathrm{O}_{2}$ in the ferE mutant compared with the wild-type strain. This suggests that FerE has an important role in oxidative stress tolerance of E. carotovora subsp. carotovora, showing for the first time a biological function for a plant ferredoxin-like protein in heterotrophic bacteria. The observed contribution to oxidative stress tolerance of FerE as well as the reduced in planta growth of the ferE mutant suggests that FerE is required for bacterial fitness during the infection process.

To investigate the overall role of QS in the oxidative stress tolerance of $E$. carotovora subsp. carotovora, we examined the
$\mathrm{H}_{2} \mathrm{O}_{2}$ tolerance of the $\operatorname{expI}$ mutant. The $\operatorname{expI}$ mutant was even more susceptible to oxidative stress than the ferE mutant, showing clearly that, in the plant pathogen E. carotovora subsp. carotovora SCC3193, QS controls oxidative stress tolerance. Earlier studies in bacteria such as Pseudomonas spp. and Burkholderia pseudomallei support our results showing an association between oxidative stress tolerance and QS (Hassett et al. 1999; Quiñones et al. 2005; Lumjiaktase et al. 2006). In Pseudomonas syringae, QS was suggested to regulate the epiphytic fitness, including traits such as oxidative stress tolerance, EPS production, and swarming motility. The oxidative stress response was shown to be in association with the alginate production (Quiñones et al. 2005). In this study, we have identified a new important factor, FerE, being part of the oxidative stress tolerance regulon. This suggests that QS regulates a diverse set of factors conferring oxidative stress tolerance. The joining of E. carotovora subsp. carotovora to the group having oxidative stress as one of the QS targets indicates that this stress response could be one of the key traits regulated by QS in general. Oxidative burst play a central role in many host-pathogen interactions; therefore, the role of a cell density-dependent mechanism as a key regulator of oxidative stress tolerance is legitimate.

In conclusion, using a transposon mutagenesis and analysis of selected mutants, we have identified previously new QS-regulated genes in the genus Erwinia. This discovery highlights the fact that the cooperative working model of ExpR1 and ExpR2 is not restricted only to the regulation of the main virulence determinants, the PCWDEs, and further deepens our understanding of the impact QS system has on different cellular activities involved in pathogen-host interactions, such as survival of oxidative stress, one of the main host defense systems.

\section{MATERIALS AND METHODS}

\section{Bacterial strains and media.}

Bacterial strains and plasmids used in this study are listed in Table 1. Escherichia coli strains were cultured in L medium (Miller 1972) at $37^{\circ} \mathrm{C}$ and Erwinia carotovora subsp. carotovora strains at $28^{\circ} \mathrm{C}$. As minimal media, M9 media was used (Miller 1972). Chloramphenicol (Cm) was added at $50 \mu \mathrm{g} \mathrm{ml}^{-1}$ and kanamycin $(\mathrm{Km})$ at $50 \mu \mathrm{g} \mathrm{ml}^{-1}$ when required and if not

Table 1. Bacterial strains used in this study

\begin{tabular}{|c|c|c|}
\hline Strain or plasmid & Genotype & Reference \\
\hline \multicolumn{3}{|l|}{$\overline{\text { Strains }}$} \\
\hline \multicolumn{3}{|l|}{ Escherichia coli } \\
\hline S17-1 $\lambda$-pir/pRG (pUT-mini-Tn5Cmr::gusA) & 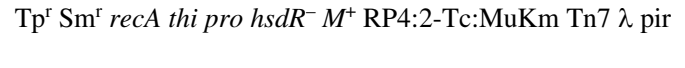 & $\begin{array}{l}\text { de Lorenzo et al. 1990; Marits } \\
\text { et al. } 1999\end{array}$ \\
\hline \multicolumn{3}{|l|}{ Erwinia carotovora subsp. carotovora } \\
\hline SCC3193 & Wild type & Saarilahti and Palva 1986 \\
\hline SCC 3065 & $\exp I:: \mathrm{km}$ in SCC 3193 background, $\mathrm{Km}^{\mathrm{r}}$ & Pirhonen et al. 1991 \\
\hline SCC6005 & expIexpR1:: $\mathrm{cm}$ in $\mathrm{SCC} 3193$ background, $\mathrm{Cm}^{\mathrm{r}}$ & Andersson et al. 1991 \\
\hline SCC906 & 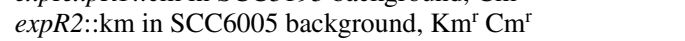 & Sjöblom et al. 2006 \\
\hline SCC908 & 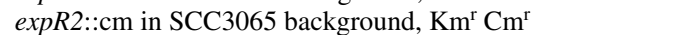 & Sjöblom et al. 2006 \\
\hline expI $r s m A$ mutant & $\Delta r s m A$ in $\mathrm{SCC} 3065$ background, $\mathrm{Km}^{\mathrm{r}}$ & R. A. Andersson (unpublished) \\
\hline SCC $802-1$ & ferE:: $\mathrm{cm}$ gusA in SCC3193 background, $\mathrm{Cm}^{\mathrm{r}}$ & This work \\
\hline SCC802 & ferE $:: \mathrm{cm}$ gus $A$ in $\mathrm{SCC} 3065$ background, $\mathrm{Km}^{\mathrm{r}} \mathrm{Cm}^{\mathrm{r}}$ & This work \\
\hline SCC 804-1 & hor:: $\mathrm{cm}$ gusA in SCC3193 background, $\mathrm{Cm}^{\mathrm{r}}$ & This work \\
\hline SCC804 & hor:: $\mathrm{cm}$ gusA in $\mathrm{SCC} 3065$ background, $\mathrm{Km}^{\mathrm{r}} \mathrm{Cm}^{\mathrm{r}}$ & This work \\
\hline \multicolumn{3}{|c|}{ 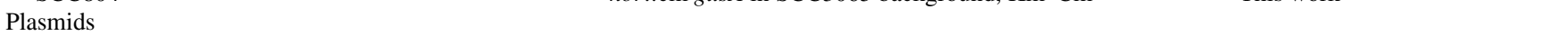 } \\
\hline pBluescript SK+ (pBSK+) & Cloning vector, $\mathrm{Amp}^{\mathrm{r}}$ & Stratagene \\
\hline pQE30 & Expression vector, Amp ${ }^{r}$ & Qiagen \\
\hline expI $I_{\mathrm{SCC} 3193}$ in $\mathrm{pBSK}+$ & $\operatorname{expI}_{S C C 3193}$ cloned into pBSK+ & Brader et al. 2005 \\
\hline pSMS30 & ferE cloned into pQE30 EcoRI and BamHI sites & This work \\
\hline pSMS31 & hor cloned into pQE30 EcoRI and BamHI sites & This work \\
\hline
\end{tabular}

${ }^{a} \mathrm{Tp}^{\mathrm{r}}, \mathrm{Sm}^{\mathrm{r}} \mathrm{Km}^{\mathrm{r}} \mathrm{Cm}^{\mathrm{r}} \mathrm{Amp}^{\mathrm{r}}$ indicates resistance to trimethoprim, streptomycin, kanamycin, chloramphenicol, and ampicillin, respectively. 
otherwise mentioned. AHSL were used at a concentration of 1 $\mu \mathrm{M}$ if not otherwise mentioned.

\section{Transposon mutagenesis and construction of mutant strains.}

For the generation of E. carotovora subsp. carotovora double mutants responsive to AHSL, the expI mutant (SCC3065) (Table 1) was used as recipient. The donor strain Escherichia coli S17-1 $\lambda$-pir containing a suicide vector pUT-miniTn5Cm ${ }^{\mathrm{r}}:$ :gusA was used in biparental matings as described by de Lorenzo and associates (1990) and Marits and associates (1999). Transconjugants were selected on L agar plates containing $\mathrm{Cm}$ and $\mathrm{Km}$. AHSL-responsive mutants were selected on $\mathrm{L}$ agar plates containing $\mathrm{XglcA}$ at $50 \mu \mathrm{g} \mathrm{ml}^{-1}$, appropriate antibiotics, and with or without $1 \mu \mathrm{M}$ 3-oxo-C6-HSL. Replicate plates with or without 3-oxo-C6-HSL were compared to identify colonies with changed color intensity in response to the presence of AHSL. The cognate AHSL for the E. carotovora subsp. carotovora SCC3193 used in this study was 3-oxoC8-HSL (Brader et al. 2005). However, the strain responds also to higher concentrations of the related but noncognate 3-oxoC6-HSL (Brader et al. 2005; Pirhonen et al. 1993). We used the 3-oxo-C6-HSL for the screening instead of the 3-oxo-C8HSL due to its commercial availability at that time.

The transposon mutants were transferred to wild-type background by generalized transduction and subsequent homologous recombination using T4GT7 phages as described previously (Pirhonen and Palva, 1988; Pirhonen et al. 1991). Northern blot analysis was used to verify that expression of the genes was indeed inactivated by the insertion (data not shown).

\section{DNA techniques.}

To identify the site of transposon insertion of the new mutants, we used arbitrary PCR (Caetano-Annoles 1993; O'Toole and Kolter 1998) and subsequent sequencing of the PCR products. In this method, the DNA flanking the insertion site is enriched in two rounds of amplification with primers specific to the ends of the Tn5 element and primers specific to the random sequence, which can anneal to chromosomal sequences flanking the transposon. Subsequently, ferE and hor probes were designed to screen a Lambda DASH library (Stratagene, La Jolla, CA, U.S.A.), containing 17- to 22-kb fragments of $E$. carotovora subsp. carotovora SCC3193, to obtain the flanking regions. FerE- and hor-positive clones were used for subsequent arbitrary PCR. All of the sequencing reactions were performed by an automatic laser fluorescent sequencer (Pharmacia, Uppsala, Sweden) at the Institute of Biotechnology (University of Helsinki, Finland).

\section{Construction of plasmids.}

The ferE and hor genes were amplified by PCR from wildtype SCC3193 genomic DNA using the primers FerE F compl (5'-CGGAATTCGTTGATTTTCTTATAAATT-3') and FerE R compl (5'-CGGGATCCTTAATATAAATTCTTTTCC-3') and Hor F compl (5'-CGGAATTCATGGAATTGCCATTAGGAT$\left.3^{\prime}\right)$ and Hor R compl (5'-CGGGATCCTTACACTTGATTTTC ATGT-3'). The 576-bp ferE PCR product and the 438-bp hor PCR product were digested with BamHI and EcoRI and ligated into $\mathrm{pQE} 30$, digested with corresponding enzymes, resulting in pSMS30 and pSMS31, respectively.

\section{RNA isolation and Northern blot analysis.}

Erwinia cells from overnight cultures were diluted 1/100 in $\mathrm{L}$ medium and grown at $28^{\circ} \mathrm{C}$. Samples for RNA isolation were taken at indicated time points and growth was monitored by measuring the optical density at $600 \mathrm{~nm}\left(\mathrm{OD}_{600}\right)$. Total RNA was isolated as described by Sambrook and associates
(1989). Northern blot analysis was performed with $10 \mu \mathrm{g}$ of total RNA separated in $1.5 \%$ formaldehyde gel. Specific digoxigenin-labeled DNA fragments for the Northern blots were amplified with PCR using the following primers: ferE $(\mathrm{Fw}) 5^{\prime}-$ GCTCATCATCTAAAAAAGACTGATC-3' and (Rev) 5'-GAT ATAGAGTGCTCCGATGATG-3' and hor (Fw) 5'-TGCAATC CAGGGATATAAC-3' and (Rev) 5'-GTTATGCAACGTGACC CA-3'; and $16 S$ rRNA primers F2115 and F2116 (Hyytiäinen et al. 2003). The blotting hybridization and digoxigenin detection was performed according to the manufacturer's instructions (Roche, Diagnostics, Basel, Switzerland).

\section{Enzyme assays.}

Cellulase (Cel) and polygalacturonase (PehA) activities were assayed from $10 \mu \mathrm{l}$ of supernatant of overnight-grown liquid cultures on corresponding enzyme indicator plates (Pirhonen et al. 1993). For GUS activity assay, Erwinia cells from overnight cultures were diluted $1 / 100$ in $\mathrm{L}$ medium and grown at $28^{\circ} \mathrm{C}$. Samples for GUS activity assay were taken at indicated time points and the growth was monitored by measuring the $\mathrm{OD}_{600}$. GUS activity was measured by using $p$-nitrophenyl $\beta$-D-glucuronide as substrate (Marits et al. 2002; Novel et al. 1974).

\section{Oxidative stress tolerance.}

To test oxidative stress tolerance cells, $\mathrm{H}_{2} \mathrm{O}_{2}$ was added directly to an overnight liquid culture to a final concentration of 20,30 , or $40 \mathrm{mM}$ and the cells were incubated for $4 \mathrm{~h}$ at $28^{\circ} \mathrm{C}$ by shaking in the dark. The cells were plated and CFU were counted both before and after the stress treatments (Andersson et al. 1999).

\section{Virulence tests.}

To test the maceration capacity, E. carotovora subsp. carotovora strains were grown overnight and diluted into $0.9 \% \mathrm{NaCl}$, and samples containing $10^{5}$ bacterial cells $\mathrm{ml}^{-1}$ were used for inoculation of 1-cm-thick potato slices (S. tuberosum cv. Van Gogh). Infected potato slices were incubated at $28^{\circ} \mathrm{C}$ for $72 \mathrm{~h}$ under humid conditions with wet tissue paper in the incubation box. The amount of soft rot was measured by scraping and subsequently weighing the rotted tissue.

A. thaliana Col-0 plants were grown in 1:1 vermiculite and peat mixture with a 12 -h light period at $22^{\circ} \mathrm{C}$, and 4 -week-old plants were used for experiments. A. thaliana Col-0 plants were infected by wounding and local inoculation of approximately $10^{4} \mathrm{CFU}$ bacteria in $0.9 \% \mathrm{NaCl}$ per leaf. The infected plants were kept in a controlled environment $\left(22^{\circ} \mathrm{C}, 12 \mathrm{~h}\right.$ of light, and high humidity) and the development of disease symptoms were documented after $48 \mathrm{~h}$. To determine bacterial growth in planta (CFU/plant) in Arabidopsis, the infected plants were homogenized into $0.9 \% \mathrm{NaCl}$ and serial dilutions of bacteria were plated on L plates with appropriate antibiotics added. Statistical analysis was performed with SPSS 10.07. The data of all replicates were normally distributed and were analyzed by one-way analysis of variance followed by Tukey's honestly significant difference post hoc test for multiple comparisons between the means.

\section{Nucleotide sequence accession number.}

The DNA sequence data determined in this study has been submitted to the DDB/EMBL/GenBank databases under accession number EU274296 (FerE) and EU274295 (Hor).

\section{ACKNOWLEDGMENTS}

This study was supported by the Helsinki Graduate School in Biotechnology and Molecular Biology, Academy of Finland (Finnish Centre of 
Excellence Programme), and Biocentrum Helsinki. We thank L. Miettinen and H. Mikkonen for excellent technical assistance, L. Paulin for the DNA sequence analysis provided by the DNA sequence core facility on the campus (Institute of Biotechnology, University of Helsinki, Finland), H. Saarilahti (University of Helsinki, Finland) for kindly providing us the SCC3193 Lambda Dash II library, and R. Andersson for kindly providing us the expI rsmA mutant.

\section{LITERATURE CITED}

Andersson, R. A., Kõiv, V., Norman-Setterblad, C. and Pirhonen, M. 1999. Role of RpoS in virulence and stress tolerance of the plant pathogen $\mathrm{Er}$ winia carotovora subsp. carotovora. Microbiology 145:3547-3556.

Bainton N. J., Stead P., Chabra, S. R., Bycroft, B. W., Salmond, G. P., Stewart, G. S., and Williams, P. 1992. $N$-(3-oxohexanoyl)-L-homoserine lactone regulates carbapenem antibiotic production in Erwinia carotovora. Biochem. J. 288:997-1004.

Barnard, A. M., and Salmond, G. P. 2007. Quorum sensing in Erwinia species. Anal. Bioanal. Chem. 387:415-423.

Beck von Bodman, S., and Farrand, S. K. 1995. Capsular polysaccharide biosynthesis and pathogenicity in Erwinia stewartii require induction by an $N$-acylhomoserine lactone autoinducer. J. Bacteriol. 177:50005008.

Bell, K. S, Sebaihia, M., Pritchard, L., Holden, M. T., Hyman, L. J., Holeva, M. C., Thomson, N. R., Bentley, S. D., Churcher, L. J., Mungall, K., Atkin, R., Bason, N., Brooks, K., Chillingworth, T., Clark, K., Doggett, J., Fraser, A., Hance, Z., Hauser, H., Jagels, K., Moule, S., Norbertczak, H., Ormond, D., Price, C., Quail, M. A., Sanders, M. Walker, D., Whitehead, S., Salmond, G. P., Birch, P. R., Parkhill, J., and Toth, I. K. 2004. Genome sequence of the enterobacterial phytopathogen Erwinia carotovora subsp. atroseptica and characterization of virulence factors. Proc. Natl. Acad. Sci. U.S.A. 101:11105-11110.

Brader, G., Sjöblom, S., Hyytiäinen, H., Sims-Huopaniemi, K. and Palva, E. T. 2005. Altering substrate chain length specificity of an acylhomoserine lactone synthase in bacterial communication. J. Biol. Chem. 280:10403-10409.

Brown, J. R. 2003. Ancient horizontal gene transfer. Nat. Rev. Genet. 4:121-132.

Burr, T., Barnard, A. M., Corbett, M. J., Pemberton, C. L., Simpson, N. J., and Salmond, G. P. 2006. Identification of the central quorum sensing regulator of virulence in the enteric phytopathogen, Erwinia carotovora: The VirR repressor. Mol. Microbiol. 59:113-125.

Burrowes, E., Baysse, C., Adams, C., and O'Gara, F. 2006. Influence of the regulatory protein RsmA on cellular functions in Pseudomonas aeruginosa PAO1, as revealed by transcriptome analysis. Microbiology $152: 405-418$

Caetano-Annoles, G. 1993. Amplifying DNA with arbitrary oligonucleotide primers. PCR Methods Appl. 3:85-92.

Chatterjee, A., Cui, Y., Liu, Y., Dumenyo, C. K., and Chatterjee, A. K. 1995. Inactivation of $r s m A$ leads to overproduction of extracellular pectinases, cellulases, and proteases in Erwinia carotovora subsp. carotovora in the absence of the starvation/cell density-sensing signal, $\mathrm{N}$-(3oxohexanoyl)-L-homoserine lactone. Appl. Environ. Microbiol. 61:1959-1967.

Chatterjee, A., Cui, Y., Hasegawa, H., Leigh, N., Dixit, V., and Chatterjee, A. K. 2005. Comparative analysis of two classes of quorum-sensing signalling systems that control production of extracellular proteins and secondary metabolites in Erwinia carotovora subspecies. J. Bacteriol. 187:8026-8038.

Chen, H., Teplitski, M., Robinson, J. B., Rolfe, B. G., and Bauer, W. D. 2003. Proteomic analysis of wild-type Sinorhizobium meliloti responses to $\mathrm{N}$-acyl homoserine lactone quorum-sensing signals and the transition to stationary phase. J. Bacteriol. 185:5029-5036.

Corbett, M., Virtue, S., Bell, K., Birch, P., Burr, T., Hyman, L., Lilley, K., Poock, S., Toth, I., and Salmond, G. 2005. Identification of a new quorum-sensing-controlled virulence factor in Erwinia carotovora subsp. atroseptica secreted via the type II targeting pathway. Mol. PlantMicrobe. Interact. 18:334-342.

Cui, Y., Madi, L., Mukherjee, A., Dumenyo, C. K., and Chatterjee, A. K. 1996. The RsmA-mutants of Erwinia carotovora subsp. carotovora strain Ecc71 overexpress $\mathrm{hrpN}_{\mathrm{Ecc}}$ and elicit a hypersensitive reactionlike response in tobacco leaves. Mol. Plant-Microbe. Interact. 9:565573

Cui, Y., Chatterjee, A., Hasegawa, H., and Chatterjee, A. K. 2006. Erwinia carotovora subspecies produce duplicate variants of ExpR, LuxR homologs that activate $r s m A$ transcription but differ in their interactions with $N$-acylhomoserine lactone signals. J. Bacteriol. 188:4715-4726.

de Lorenzo, V., Herrero, M., Jakubzik, U., and Timmis, K. N. 1990. MiniTn5 transposon derivatives for insertion mutagenesis, promoter prob- ing, and chromosomal insertion of cloned DNA in gram-negative eubacteria. J. Bacteriol. 172:6568-6572.

Eberhard, A., Burlingame, A. L., Eberhard, C., Kenyon, G. L., Nealson, K. H., and Oppenheimer, N. J. 1981. Structural identification of autoinducer of Photobacterium fischeri luciferase. Biochemistry 20:24442449.

Engebrecht, J., and Silverman, M. 1984. Identification of genes and gene products necessary for bacterial bioluminescence. Proc. Natl. Acad. Sci. U.S.A. 81:4154-4158.

Fineran, P. C., Slater, H., Everson, L., Hughes, K., and Salmond, G. P. 2005. Biosynthesis of tripyrrole and beta-lactam secondary metabolites in Serratia: Integration of quorum sensing with multiple new regulatory components in the control of prodigiosin and carbapenem antibiotic production. Mol. Microbiol. 56:1495-1517.

Floss, B., Igloi, G. L., Cassier-Chauvat, C., and Mühlenhoff, U. 1997. Molecular characterisation and overexpression of the pet $F$ gene from Synechococcus elongatus: Evidence for a second site of electrostatic interaction between ferredoxin and the PSI-D subunit. Photosynth. Res. 54:63-71

Fuqua, C., and Greenberg, E. P. 2002. Listening in on bacteria: Acyl-homoserine lactone signalling. Nat. Rev. Mol. Cell. Biol. 3:685-695.

Fuqua, C., Parsek, M. R., and Greenberg, E. P. 2001. Regulation of gene expression by cell-to-cell communication: Acyl-homoserine lactone quorum sensing. Annu. Rev. Genet. 35:439-468.

Garcia-Vallve, S., Guzman, E., Montero, M. A., and Romeu, A. 2003. HGT-DB: A database of putative horizontally transferred genes in prokaryotic complete genomes. Nucleic Acids Res 31:187-189.

Hanke, G. T., Kimata, A. Y., Taniguchi, I., and Hase, T. 2003. A post genomic characterization of Arabidopsis ferredoxins. Plant Physiol. 134:255-264.

Hassett, D. J., Ma, J. F., Elkins, J. G., McDermott, T. R., Ochsner, U. A., West, S. E., Huang, C. T., Fredericks, J., Burnett, S., Stewart, P. S, McFeters, G., Passador, L., and Iglewski, B. H. 1999. Quorum sensing in Pseudomonas aeruginosa controls expression of catalase and superoxide dismutase genes and mediates biofilm susceptibility to hydrogen peroxide. Mol. Microbiol. 34:1082-1093.

Heurlier, K., Williams, F., Heeb, S., Dormond, C., Pessi, G., Singer, D., Camara, M., Williams, P., and Haas, D. 2004. Positive control of swarming, rhamnolipid synthesis, and lipase production by the posttranscriptional RsmA/RsmZ system in Pseudomonas aeruginosa PAO1. J. Bacteriol. 186:2936-2945.

Hinton, J. C. D., Grll, D. R., Lalo, D., Plastow, G. S., and Salmond, G. P. C. 1990. Sequence of the peh gene of Erwinia carotovora: Homology between Erwinia and plant enzymes. Mol. Microbiol. 4:1029-1036.

Holden, M. T., McGowan, S. J., Bycroft, B. W., Stewart, G. S., Williams, P., and Salmond, G. P. 1998. Cryptic carbapenem antibiotic production genes are widespread in Erwinia carotovora: Facile trans activation by the carR transcriptional regulator. Microbiology 144:1495-1508.

Hyytiäinen, H., Sjöblom, S., Palomäki, T., Tuikkala, A., and Palva, E. T. 2003. The PmrA-PmrB two-component system responding to acidic $\mathrm{pH}$ and iron controls virulence in the plant pathogen Erwinia carotovora ssp. carotovora. Mol. Microbiol. 50:795-807.

Jones, S., Yu, B., Bainton, N. J., Birdsall, M., Bycroft, B.W., Chhabra, S. R., Cox, A. J., Golby, P., Reeves, P. J., Stephens, S., Winson, M. K., Salmond, G. P., Stewart, G. S., and Williams, P. 1993. The lux autoinducer regulates the production of exoenzyme virulence determinants in Erwinia carotovora and Pseudomonas aeruginosa. EMBO (Eur. Mol. Biol. Organ.) J. 12:2477-2482.

Koo, M. S., Lee, J. H., Rah, S. Y., Yeo, W. S., Lee, J. W., Lee, K. L., Koh, Y. S., Kang, S. O., and Roe, J. H. 2003. A reducing system of the superoxide sensor SoxR in Escherichia coli. EMBO (Eur. Mol. Biol. Organ.) J. 22:2614-2622.

Koonin, E. V., Makarova, K. S., and Aravind, L. 2001. Horizontal gene transfer in prokaryotes: Quantification and classification. Annu. Rev. Microbiol. 55:709-742.

Kuhl, J. C., Havey, M. J., Martin, W. J., Cheung, F., Yuan, Q., Landherr, L., Hu, Y., Leebens-Mack, J., Town, C. D., and Sink K. C. 2005. Comparative genomic analyses in Asparagus. Genome. 48:1052-1060.

Lazdunski, A. M., Ventre, I., and Sturgis, J. N. 2004. Regulatory circuits and communication in gram-negative bacteria. Nat. Rev. Microbiol. 2:581-592.

Lumjiaktase, P., Diggle, S. P., Loprasert, S., Tungpradabkul, S., Daykin, M., Camara, M., Williams, P., and Kunakorn, M. 2006. Quorum sensing regulates dpsA and the oxidative stress response in Burkholderia pseudomallei. Microbiology 152:3651-3659.

Marchler-Bauer, A., Anderson, J. B., Derbyshire, M. K., DeWeese-Scott, C., Gonzales, N. R., Gwadz, M., Hao, L., He, S., Hurwitz, D. I., Jackson, J. D., Ke, Z., Krylov, D., Lanczycki, C. J., Liebert, C. A., Liu, C., Lu, F., Lu, S., Marchler, G. H., Mullokandov, M., Song, J. S., Thanki, N., Yamashita, R. A., Yin, J. J., Zhang, D., and Bryant, S. H. 
2007. CDD: A conserved domain database for interactive domain family analysis. Nucleic Acids Res. 35: D237-240.

Marits, R., Koiv, V., Laasik, E., and Mae, A. 1999. Isolation of an extracellular protease gene of Erwinia carotovora subsp. carotovora strain SCC3193 by transposon mutagenesis and the role of protease in phytopathogenicity. Microbiology 145:1959-1966.

Marits, R., Tshuikina, M., Pirhonen, M., Laasik, E., and Mäe, A. 2002. Regulation of the expression of prtW::gusA fusions in Erwinia carotovora subsp. carotovora. Microbiology 148:835-842.

Mazouni, K., Domain, F., Chauvat, F., and Cassier-Chauvat, C. 2003. Expression and regulation of the crucial plant-like ferredoxin of cyanobacteria. Mol. Microbiol. 49:1019-1029.

McGowan, S., Sebaihia, M., Jones, S., Yu, B., Bainton, N., Chan, P. F., Bycroft, B., Stewart, G. S., Williams, P., and Salmond, G. P. 1995. Carbapenem antibiotic production in Erwinia carotovora is regulated by CarR, a homologue of the LuxR transcriptional activator. Microbiology 141:541-550.

McGowan, S. J., Barnard, A. M., Bosgelmez, G., Sebaihia, M., Simpson, N. J., Thomson, N. R., Todd, D. E., Welch, M., Whitehead, N. A., and Salmond, G. P. 2005. Carbapenem antibiotic biosynthesis in Erwinia carotovora is regulated by physiological and genetic factors modulating the quorum sensing-dependent control pathway. Mol. Microbiol. 55:526-545.

Miller, J. H. 1972. Experiments in Molecular Genetics. Cold Spring Harbor Laboratory, Cold Spring Harbor, NY, U.S.A.

Minogue, T. D., Wehland-von, Trebra, M., Bernhard, F., and von Bodman S. B. 2002. The autoregulatory role of EsaR, a quorum-sensing regulator in Pantoea stewartii ssp. stewartii: Evidence for a repressor function. Mol. Microbiol. 44:1625-1635.

Minogue, T. D., Carlier, A. L., Koutsoudis, M. D., and von Bodman, S. B. 2005. The cell density-dependent expression of stewartan exopolysaccharide in Pantoea stewartii ssp. stewartii is a function of EsaR-mediated repression of the $r c s A$ gene. Mol. Microbiol. 56:189-203.

Novel, G., Didier-Fichet, M. L., and Stoeber, F. 1974. Inducibility of betaglucuronidase in wild-type and hexuronate-negative mutants of Escherichia coli K-12. J. Bacteriol. 120:89-95.

Ollagnier-de Choudens, S., Nachin, L., Sanakis, Y., Loiseau, L., Barras, F., and Fontecave, M. 2003. SufA from Erwinia chrysanthemi. Characterization of a scaffold protein required for iron-sulfur cluster assembly. J. Biol. Chem. 278:17993-8001.

O'Toole, G. A., and Kolter, R. 1998. Initiation of biofilm formation in Pseudomonas fluorescens WCS365 proceeds via multiple, convergent signalling pathways: A genetic analysis. Mol. Microbiol. 28:449-461.

Outten, F. W. 2007 Iron-sulfur clusters as oxygen-responsive molecular switches. Nat. Chem. Biol. 3:206-207.

Pappas, K. M., Weingart, C. L., and Winans, S. C. 2004. Chemical communication in proteobacteria: Biochemical and structural studies of signal synthases and receptors required for intercellular signalling. Mol. Microbiol. 53:755-769.

Parsek, M. R., and Greenberg, E. P. 2000. Acyl-homoserine lactone quorum sensing in gram-negative bacteria: A signaling mechanism involved in associations with higher organisms. Proc. Natl. Acad. Sci. U.S.A. 97:8789-8793.

Pemberton, C. L., Whitehead, N. A., Sebaihia, M., Bell, K. S., Hyman, L. J., Harris, S. J., Matlin, A. J., Robson, N. D., Birch, P. R., Carr, J. P., Toth, I. K., and Salmond, G. P. 2005. Novel quorum-sensing-controlled genes in Erwinia carotovora subsp. carotovora: Identification of a fungal elicitor homologue in a soft-rotting bacterium. Mol. Plant-Microbe. Interact. 18:343-353.

Perombelon, M. C. M. 2002. Potato diseases caused by soft rot erwinias: An overview of pathogenesis. Plant Pathol. 51:1-12.

Pessi, G., Williams, F., Hindle, Z., Heurlier, K., Holden, M. T., Camara, M., Haas, D., and Williams, P. 2001. The global posttranscriptional regulator RsmA modulates production of virulence determinants and $\mathrm{N}$ acylhomoserine lactones in Pseudomonas aeruginosa. J. Bacteriol. 183:6676-6683.

Pirhonen, M., and Palva E. T. 1988. Occurance of bacteriophage T4 receptor in Erwinia carotovora. Mol. Gen. Genet. 214:170-172.

Pirhonen, M., Saarilahti, H., Karlsson, M.-B., and Palva, E. T. 1991. Identification of pathogenicity determinants of Erwinia carotovora subsp. carotovora by transposon mutagenesis. Mol. Plant-Microbe Interact. 4:276-283.

Pirhonen, M., Flego, D., Heikinheimo, R., and Palva E. T. 1993. A small diffusible signal molecule is responsible for the global control of virulence and exoenzyme production in the plant pathogen Erwinia carotovora. EMBO (Eur. Mol. Biol. Organ.) J. 12:2467-2476.

Qin, N., Callahan, S. M., Dunlap, P. V., and Stevens, A. M. 2007. Analysis of LuxR regulon gene expression during quorum sensing in Vibrio fischeri. J. Bacteriol. 189:4127-4134.

Qin, Y., Luo, Z. Q., Smyth, A. J., Gao, P., Beck von Bodman, S., and Farrand, S. K. 2000. Quorum-sensing signal binding results in dimerization of TraR and its release from membranes into the cytoplasm. EMBO (Eur. Mol. Biol. Organ.) J. 19:5212-5221.

Quiñones, B., Dulla, G., and Lindow, S. E. 2005. Quorum sensing regulates exopolysaccharide production, motility, and virulence in Pseudomonas syringae. Mol. Plant-Microbe Interact. 18:682-693.

Saarilahti, H. T., and Palva, E. T. 1986. Major outer membrane proteins in the phytopathogenic bacteria Erwinia carotovora subsp. carotovora and subsp. atroseptica. FEMS (Fed. Eur. Microbiol. Soc.) Microbiol. Lett. 35:267-270.

Saarilahti, H. T., Heino, P., Pakkanen, R., Kalkkinen, N., Palva, I., and Palva, E. T. 1990. Structural analysis of the pehA gene and characterization of its protein product, endopolygalacturonase, of Erwinia carotovora subspecies carotovora. Mol. Microbiol. 4:1037-1044.

Sambrook, J., Fritsch, E. F., and Maniatis, T. A. 1989. Molecular Cloning: A Laboratory Manual, 2nd ed. Cold Spring Harbor Laboratory, Cold Spring Harbor, NY, U.S.A.

Schuster, M., Lostroh, C. P., Ogi, T., and Greenberg, E. P. 2003. Identification, timing, and signal specificity of Pseudomonas aeruginosa quorum-controlled genes: A transcriptome analysis. J. Bacteriol. 185:20662079.

Sjöblom, S., Brader, G., Koch, G., and Palva, E. T. 2006. Cooperation of two distinct ExpR regulators controls quorum sensing specificity and virulence in the plant pathogen Erwinia carotovora. Mol. Microbiol. 60:1474-1489.

Slater, H., Crow, M., Everson, L., and Salmond, G. P. 2003. Phosphate availability regulates biosynthesis of two antibiotics, prodigiosin and carbapenem, in Serratia via both quorum-sensing-dependent and -independent pathways. Mol. Microbiol. 47:303-320.

Thompson, J. D., Higgins, D. G., and Gibson, T. J. 1994. CLUSTAL W: Improving the sensitivity of progressive multiple sequence alignment through sequence weighting, positions-specific gap penalties and weight matrix choice. Nucleic Acids Res. 22:4673-4680.

Thomson, N. R., Cox, A, Bycroft, B. W., Stewart, G. S, Williams, P., and Salmond, G. P. 1997. The rap and hor proteins of Erwinia, Serratia and Yersinia: A novel subgroup in a growing superfamily of proteins regulating diverse physiological processes in bacterial pathogens. Mol. Microbiol. 26:531-544.

Thomson, N. R., Crow, M. A., McGowan, S. J., Cox, A., and Salmond, G. P. 2000. Biosynthesis of carbapenem antibiotic and prodigiosin pigment in Serratia is under quorum sensing control. Mol. Microbiol. 36:539556.

Toth, I. K., Pritchard, L., and Birch, P. R. J. 2006. Comparative genomics reveals what makes an enterobacterial plant pathogen. Annu. Rev. Phytopathol. 44:305-336.

van Elsas, J. D., Turner, S., and Bailey, M. J. 2003. Horizontal gene transfer in the phytosphere. New Phytol. 157:525-537.

Wagner, V. E., Bushnell, D., Passador, L., Brooks, A. I., and Iglewski, B. H. 2003. Microarray analysis of Pseudomonas aeruginosa quorumsensing regulons: Effects of growth phase and environment. J. Bacteriol. 85:2080-2095.

Waters, C. M., and Bassler, B. L. 2005. Quorum sensing: Cell-to-cell communication in bacteria. Annu. Rev. Cell. Dev. Biol. 21:319-346.

Whitehead, N. A., Barnard, A. M., Slater, H., Simpson, N. J., and Salmond, G. P. 2001. Quorum-sensing in gram-negative bacteria. FEMS (Fed. Eur. Microbiol. Soc.) Microbiol. Rev. 25:365-404.

Whitehead, N. A., Byers, J. T., Commander, P., Corbett, M. J., Coulthurst, S. J., Everson, L., Harris, A. K., Pemberton, C. L., Simpson, N. J., Slater, H., Smith, D. S., Welch, M., Williamson, N., and Salmond, G. P. 2002. The regulation of virulence in phytopathogenic Erwinia species: Quorum sensing, antibiotics and ecological considerations. Antonie Leeuwenhoek. 81:223-231.

Winson, M. K., Camara, M., Latifi, A., Foglino, M., Chhabra, S. R., Daykin, M., Bally, M., Chapon, V., Salmond, G. P., Bycroft, B. W., Lazdunski, A., Stewart, G. S. A. B., and Williams, P. 1995. Multiple $N$ acyl-L-homoserine lactone signal molecules regulate production of virulence determinants and secondary metabolites in Pseudomonas aeruginosa. Proc. Natl. Acad. Sci. U.S.A. 92:9427-9431.

Zhang, L., Murphy, P. J., Kerr, A., and Tate, M. E. 1993 Agrobacterium conjugation and gene regulation by $N$-acyl-L-homoserine lactones. Nature 362:446-448.

\section{AUTHOR-RECOMMENDED INTERNET RESOURCE}

Swiss Institute of Bioinformatics EMBnet server: www.ch.embnet.org 